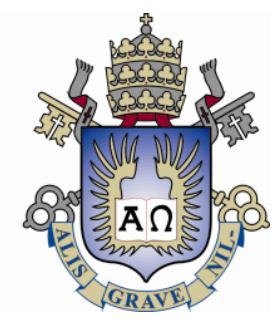

Julia Bonecker Lora

\title{
CENÁRIOS FUTUROS SUSTENTÁVEIS PARA O DESIGN: Criando ambientes para a concepção de produtos inovadores baseados na sustentabilidade
}

Dissertação apresentada ao Programa de PósGraduação em Design da PUC-Rio como requisito parcial para obtenção do título de Mestre em Design.

Orientador: Prof. Cláudio Freitas de Magalhães 


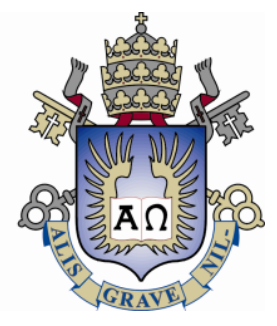

Julia Bonecker Lora

\section{CENÁRIOS FUTUROS SUSTENTÁVEIS PARA O DESIGN: Criando ambientes para a concepção de produtos inovadores baseados na sustentabilidade}

Dissertação apresentada ao Programa de PósGraduação em Design da PUC-Rio como requisito parcial para obtenção do grau de Mestre em Design. Aprovada pela Comissão Examinadora abaixo assinada.

Prof. Cláudio Freitas de Magalhães Orientador Departamento de Arte\& Design - PUC-RIO

Prof. Alfredo Jefferson de Oliveira Departamento de Artes \& Design - PUC-Rio

Prof.. . Cyntia Santos M. de Sousa Centro Universitário SENAC - SP

Prof. - Denise Berruezo Portinari Coordenadora Setorial do Centro de Teologia e Ciências

Humanas - PUC-Rio 
Todos os direitos reservados. É proibida a reprodução total ou parcial do trabalho sem a autorização da universidade, da autora e da orientadora.

\section{Julia Bonecker Lora}

Graduada em Comunicação Social com ênfase em Publicidade e Propaganda pela Pontifícia Universidade Católica do Rio de Janeiro (2007). Integrou a equipe do Laboratório de Gestão em Design da PUC-Rio monitorando o Curso de Especialização em Design de Jóias e o Curso de Extensão Design Trends Forecasts (2006 - 2010). Cursou Marketing de Moda (SENAI Cetiqt). Integrou a equipe do Projeto INOTEC, fomentador de novas tecnologias para o design de jóias, na PUC-Rio (2008 - 2009) e foi Trainee Corporativa na Lojas Renner S.A (2011). Atualmente é Consultora de Projetos na Lojas Renner S.A., gerenciando o Núcleo de Pesquisa do Departamento de Estilo, com foco em Pesquisa de Tendências e Comportamentor do Consumidor.

Ficha Catalográfica

Lora, Julia Bonecker

Cenários futuros sustentáveis para o design: criando ambientes para a concepção de produtos inovadores baseados na sustentabilidade / Julia Bonecker Lora ; orientador: Cláudio Freitas de Magalhães. - 2011. 160 f. : il. (color.) ; $30 \mathrm{~cm}$

Dissertação
Universidade Católica do Rio de Janeiro, Departamento de Artes e Design, 2011. Inclui bibliografia

1. Artes e design - Teses. 2. Design. 3. Cenários futuros. 4. Inovação. 5. Sustentabilidade. 6. Moda. I. Magalhães, Cláudio Freitas de. II. Pontifícia Universidade Católica do Rio de Janeiro. Departamento de Artes \& Design. III. Título. 


\section{Agradecimentos}

Ao meu querido orientador Claudio Magalhães. Mais que um orientador, um amigo que admiro muito a forma de olhar o mundo e me ajudou em meu crescimento profissional.

À Cidda Siqueira, minha "mãe acadêmica". Com sua disciplina e rigor teórico é um grande exemplo. Sem você esse trabalho não seria possível.

Aos queridos parceiros e colegas do LGD: Ida, Aline, Flavia, Mônica, Tatiana, Luiz, Ana Julia, Nathalia. Seus concelhos foram preciosos e a amizade é um grande presente.

Aos professores Alfredo Jefferson, Alberto Cipiniuk, Vera Damazio, Everardo Rocha, Claudia Montalvão e Nilton Gamba, que tornaram essa jornada muito mais interessante do que eu poderia esperar.

À PUC-Rio e em especial a todo o Departamento de Artes e Design pelo apoio e carinho.

À CAPES pelos auxílios concedidos, que sem eles, este trabalho não seria possível.

Às minhas amigas Patricia, Luna, Julia, Gabriela, Daniela, Carolzinha, Renata, Larissa, Yara e Gisa que sempre me incentivaram e fazem da minha juventude um momento muito especial.

Aos meus amigos "porto alegrenses" do Brasil inteiro! Vocês fizeram destes últimos meses "encantadores" e inesquecíveis em minha vida!

À Carol, Jô, Duda, Bia, Thomas, Helena, Louise, Luiz e Victor. Pela recente, porém forte amizade e companheirismo. Vocês foram essenciais nos últimos tempos.

À Lojas Renner. Pelo cuidado e presteza em tornar esse trabalho possível.

Aos colaboradores das Lojas Renner que participaram do Workshop, Luiz, Tiago, Filipe, Helena, Juliana e Aline. Suas ideias e dedicação tornaram o resultado desse trabalho muito mais rico do que eu poderia esperar.

Ao Santiago. O melhor namorado do mundo e sem dúvida uma grande inspiração em minha vida.

Ao meu irmão, Leandro. Uma pessoa única, que também é uma grande fonte de inspiração.

E aos meus pais pela educação, dedicação, apoio e amor incondicionais. 


\section{Resumo}

Lora, Julia Bonecker. Magalhães, Cláudio Freitas de. Cenários futuros sustentáveis para o design: Criando ambientes para a concepção de produtos inovadores baseados na sustentabilidade. Rio de Janeiro, 2011. 160p. Dissertação de Mestrado - Departamento de Artes e Design, Pontifícia Universidade Católica do Rio de Janeiro.

A sustentabilidade é vista como macro tendência nos dias de hoje. Esta dissertação propõe o desenvolvimento de um método de cenários futuros adequado ao design com foco na sustentabilidade. Visa promover uma visão critica do contexto atual e futuro do projeto motivando o desenvolvimento inovador dentro do paradigma sustentável. Acredita-se que através da técnica de cenários futuros é possível compreender de maneira estratégica, ambientes propícios à sustentabilidade incremental ou radical. A partir desses cenários é possível que as empresas construam uma visão de curto e longo prazo e adequemse antecipadamente a novas condições do seu ambiente de atuação. Para atingir os objetivos buscaram-se referências sobre estudos do futuro, com foco na prospecção de cenários, sustentabilidade e a sustentabilidade na moda. Também foi aplicado o método proposto em uma grande rede de varejo de moda brasileira. Para estar adequada ao processo de design, a aplicação teve duração de um dia de trabalho no formato de workshop reunindo uma equipe multidisciplinar. Foi possível prospectar cenários e construir narrativas que irão auxiliar no desenvolvimento de estratégias para a criação de produtos e serviços inovadores e sustentáveis no segmento de moda. Fundamentalmente, a prospecção de cenários funcionou como um processo de entendimento sobre a situação atual e futura da empresa em relação à sustentabilidade.

\section{Palavras-chave}

Design; Cenários Futuros; Inovação; Sustentabilidade; Moda. 


\section{Abstract}

Lora, Julia Bonecker. Magalhães, Cláudio Freitas de. (Advisor) Future scenarios for sustainable design: Creating enviroments for the design of innovative products based on sustainability. Rio de Janeiro, 2011. 160p. Dissertação de Mestrado - Departamento de Artes e Design, Pontifícia Universidade Católica do Rio de Janeiro.

Nowadays sustainability is seen as a macro trend. This study proposes the development of a method suitable for design future scenarios with a focus on sustainability. It aims to promote a critical view of the current and future context of the project promoting the development of innovative sustainable paradigm. It is believed that through the technique of future scenarios is possible to understand strategically, environments likely to incremental or radical sustainability. From these scenarios it is possible for companies to build a vision of short and long term and to suit the new conditions of their work environment. To achieve the objectives of this study, a searching of references by future studies was demanded, with a focus on a creation of scenarios, sustainable and self sustainable fashion. Also the method was applied in a large brazilian retail fashion store. To be suitable for the design process, the application lasted one working day in the form of a workshop bringing together a multidisciplinary team. It was possible to construct narratives and exploring scenarios that will assist in developing strategies for creating products and innovation services and sustainable in the fashion segment. Fundamentally, the creation of scenarios worked as a process of understanding the current situation and future of the company in relation to sustainability.

\section{Keywords}

Design; futures scenarios; innovation; sustainability; fashion. 


\section{Sumário}

1. Introdução 11

1.1. Problema 13

1.2. Objeto da pesquisa $\quad 15$

1.3. Objetivos 15

1.3.1. Objetivo Geral 15

1.3.2. Objetivos Específicos $\quad 15$

1.4. Hipótese 16

1.5. Justificativa 16

1.6. Métodos e técnicas de pesquisa 28

2. A sustentabilidade como um novo paradigma 31

2.1. Produção e consumo: o modo de produção capitalista e a sustentabilidade

2.2. Algumas soluções inovadoras e sustentáveis existentes no design

39

2.3. Estratégias para o ecodesign: indicadores de sustentabilidade 41

2.3.1. Ecodesign incremental 43

2.3.2. Novos Conceitos em Ecodesign 45

2.4. Um futuro onde a sustentabilidade será imperativa 47

2.5. Inovação e sustentabilidade $\quad 48$

2.6. A sustentabilidade na moda $\quad 49$

3. Os estudos do futuro e o design de moda 54

3.1. A importância de se estudar o futuro 54

3.2. Estudos do futuro na indústria da moda: a pesquisa de tendências ou fashion forecasting

3.3. A evolução da pesquisa de tendências no setor da moda 63

3.4. Os estudos do futuro nas corporações: a contextualização da pesquisa de tendências como importante ferramenta no ambiente empresarial

3.4.1. Casos de estratégias empresariais para a previsão de futuros com design

3.5. Cenários futuros: uma técnica dos estudos do futuro $\quad 74$

3.5.1. Histórico da construção de cenários 76

$\begin{array}{ll}\text { 3.5.2. Conceitos e definições } & 79\end{array}$

3.5.3. As metodologias 84

3.5.4. Elementos de um cenário $\quad 86$

$\begin{array}{ll}\text { 3.5.5. Cenários futuros e o design } & 91\end{array}$

4. Propondo uma abordagem para a construção de cenários 93

4.1. Aplicação do método de cenários futuros em empresa de varejo de moda

5. Conclusões 
6. Referências Bibliográficas

7. Anexos 


\section{Lista de Figuras}

Figura 1: Informação de Mercado utilizada por especialistas de design

Figura 2: Apresentação do portal WGSN de "silhuetas chave" para o outono - inverno 2012 / 2013

Figura 3: Espectros das Atividade de Design

Figura 4: Elementos da Especificação Parcial de Projeto de Produto

Figura 5: Elementos de Especificação do Design de Produto

Figura 6: Equalização de cada um dos itens dos Elementos de Especificação de Design do Produto, com relação à sustentabilidade

Figura 7: Roda da Ecoconcepção

Figura 8: "Caneta de luz" - produto desenvolvido no projeto Sense and Simplicity da Philips

Figura 9: "Herbarium" - produto desenvolvido no projeto Sense and Simplicity da Philips

Figura 10: Modelo de Fronteiras Administrativas do Design

Figura 11: Fluxograma da metodologia proposta de construção de cenários

Figura 12: Workshop de Cenários Futuros em empresa varejista de moda com a participação de colaboradores 


\section{Lista de Quadros}

Quadro 1: Classificação dos métodos de estudos do futuro 58

Quadro 2: Exemplo de Matriz de Análise Estrutural 99

Quadro 3: Tabela de Análise da Estratégia dos Atores 100

Quadro 4: Tabela de Impacto Imprevisibilidade 101

Quadro 5: Matriz de forças motrizes 102

Quadro 6: Matriz de cenários 103

Quadro 7: Matriz de análise estrutural do workshop na empresa de varejo de moda

Quadro 8: Tabela de análise das estratégias dos atores no workshop aplicado na empresa de varejo de moda

Quadro 9: Tabela de impacto e imprevisibilidade das forças motrizes

Quadro 10: Matriz de impacto X imprevisibilidade do Workshop da empresa varejista de moda

Quadro 11: Matriz de cenários do Workshop da empresa varejista de moda 